\title{
Poesía argentina reciente: objetos y series (entre el objet trouvé, el resto histórico y el souvenir)
}

Ana Porrúa

Universidad Nacional de Mar del Plata

“Não há página em branco. Objetivamente há uma página em branco - quer dizer, uma falsa objetividade para o terceiro que olha -, mas sua própria página está atestada, completamente atestada. E esse será o problema para conseguir escrever: é que a página está tão abarrotada que não tem sequer lugar para inserir o que quer que seja. De modo que escrever será fundamentalmente apagar, será fundamentalmente suprimir (...). Os pintores tem empregado uma palavra (...) que se impôs para designar aquilo do que está cheia a tela antes que o pintor comece o clichê. A tela está cheia de clichês."

Gilles Deleuze $^{1}$

"Quando se pinta um quadro, inclusive se for abstrato, há sempre uma espécie de recheio obrigatório."

Marcel Duchamp ${ }^{2}$

${ }^{1}$ DELEUZE, 2012, p. 53-55.

${ }^{2}$ Citado por CABANNE, 1972, p. 8. 


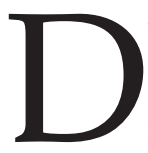

uchamp piensa el cuadro a partir del marco; el marco delimita una zona, dice, que impone una pulsión de rellenado. Entonces, rellenar es el gesto al que obliga el límite que no es sólo material. La cita de Duchamp puede leerse en relación con la de Deleuze y su idea sobre la inexistencia de la tela en blanco, de la página en blanco (tan mentada en la tradición literaria). No se trata de rellenar, para Deleuze, sino justamente de limpiar, de sacar lo que está allí. Siempre que se escribe un poema, el escritor debe desmenuzar y hasta borrar lo que la página trae escrito, como una memoria de la poesía.

Podría indagarse qué hay en la poesía en el momento en que los poetas argentinos de los '90 comienzan a escribir. ¿Qué desean o deben sacar de la página? ¿Qué voces se han convertido en ruido para ellos, qué modulaciones? ¿Acallar a Juan Gelman? ¿Laminar más que borrar lo político que la poesía de los ‘60 puso en el centro y los bordes del poema? ¿Limpiar de nostalgia las figuras, siguiendo el mandato de Leónidas Lamborghini o, en otro extremo, de Néstor Perlongher? ¿Alisar el rodeo, el pliegue neobarroco? Todas estas preguntas se asientan sobre alguna certeza; sin embargo, vuelvo a esta cuestión de la superficie sobre la que se escribe (repito, no es sólo material), y quisiera agregar a esta figura de la tela, la de la mesa o el panel, que DidiHuberman trae a colación cuando analiza el Atlas Mnemosyne, esa extraña historia crítica del arte de Aby Warburg. Warburg juntaba imágenes en una tela. Trabajaba con la tela en posición horizontal, sobre una mesa. La horizontalidad es la que permite el movimiento de las imágenes, su combinación, el montaje. La modalidad del Atlas se asienta en un pensamiento de imágenes y en la idea de correspondencias secretas, para Didi-Huberman. ${ }^{3}$

\footnotetext{
${ }^{3}$ Didi-Huberman aborda la doble significación del término latino tabula o del francés tableaux, como cuadro y como mesa, para diferenciarlas como soportes. Mientras que el primero habilitaría "la inscripción de una obra que pretende ser definitiva ante la historia", la unicidad; la segunda ofrece
} 
Puedo pensar la poesía sobre una mesa de este tipo; más que para el ejercicio de la escritura del poema, sospecho que la mesa es un dispositivo para el ejercicio crítico. No pienso, entonces, en un solo poema sino en ciertas persistencias en una zona de la poesía argentina de los '90. En términos plásticos, la poesía de los '90 se llena de objetos, de cosas. O, para decirlo de otro modo, se trata de un corpus en el que los objetos son centrales. Podemos recorrer una trama, por poemas de uno y otro autor, por fragmentos de poemas y ver qué redes de objetos se arman allí; es más, podemos armar esas redes, combinar los distintos objetos sobre una mesa, según su procedencia, su configuración, sus funciones, la temporalidad que los atraviesa. Hay objetos de uso cotidiano, utensilios muchas veces; objetos artesanales e industriales, máquinas, carteles, puentes, barcos, pero también cisnes de cemento; objetos de consumo, adornos, estampas. El poeta recoge / mira cosas. La mayor parte de las veces registra pero también desplaza las cosas de un orden a otro, o da cuenta de ese desplazamiento. Entonces, una budinera es la imagen de la letra $\mathrm{O}$ en $\mathrm{Al}$ pie de la letra de Mario Ortiz, como si la tipografía estuviese en los objetos mismos; ${ }^{4}$ entonces, un cisne

"la apertura continua de nuevas posibilidades, nuevos encuentros, nuevas multiplicidades, nuevas configuraciones" (DIDI-HUBERMAN, 2010, p. 18-19). ${ }^{4}$ ORTIZ, 2010, p. 37: "La budinera alargada que podía estirarse o encogerse según la necesidad, era una " $\mathrm{I}$ "; la redonda de aluminio con un hueco al medio era la " $\mathrm{O}$ ". Entonces, ella barnizaba el interior con un pedacito de manteca, le espolvoreaba harina y vertía la mezcla cruda, ayudándose con una cuchara. También allí se hundía mi dedo para saborear esa pasta amarillenta y azucarada, (...)". El mismo gesto se destaca en relación con las letras de plástico, las "de mi juego": "En su reverso eran huecas, de manera que si de frente y perfil se veía una lisa superficie voluminosa de pulidas aristas, agudos vértices, abultamientos e invaginaciones más o menos pronunciados según la letra en cuestión, en su cara posterior una cavidad acanalada formada por el frente y las paredes laterales, y en las que cabía mi dedo meñique, $(. . .)^{\prime \prime}$. 
- esa figura omnipresente del modernismo hispanoamericano, cargada y sobrecargada de simbología, incluso de carácter alegórico en la poesía de Rubén Darío y, antes, de Baudelairedejará definitivamente el lago poético en "Once maneras de contemplar un cisne" de Marcelo Díaz, para convertirse en un adorno de jardín, una maceta para los geranios, un objeto kitsch, o mejor, "berreta", ese calificativo que da título al libro de 1998, y que es un argentinismo utilizado para nombrar objetos de poco valor, falsificaciones. El objeto antes poético llega a este poema como objeto de uso, de factura siempre industrial, asociado a ideas de belleza populares, barriales. Y está allí, además, armando una genealogía: “Que se vea en él, aunque no siempre,/ cifrada la memoria familiar". ${ }^{5}$ ¿Objetos de un orden familiar? ¿Objetos de uso convertidos en formas de la

${ }^{5}$ DÍAZ, 1998, p. 22. El título del poema emula el de Wallace Stevens, "Trece maneras de mirar a un mirlo" ("Thirteen Ways of Looking at a Blackbird" from The Collected Poems of Wallace Stevens. Copyright 1954 by Wallace Stevens). Transcribo aquí fragmentos del poema de Díaz: "Gruesas hojas de acelga, bajo esta luz,/ y geranios blancos en el lomo del cisne/ y geranios rojos en el cantero, bajo el tendal/ que ahora, ya cercano el mediodía exhibe/ sábanas blancas y sábanas azules./ / II Un cisne de cemento nunca es blanco./ Se advierte, al acercarse, impureza en su textura,/ piedras que el tiempo ha dejado a la vista,/ grumos de arena, ademanes torpes / en su hipotético andar. / / III Un cisne de cemento duerme/ en el ocre de unos caños de desagüe,/ entre hojas de acelga y ramos / de perejil que alternan/ con un verde más claro,/ y el violeta, difuso,/ en la mata de lavanda.// IV Sus alas de cemento le impiden caminar. / / V Su signo es la carencia de mesura/ y utilidad. Quince kilos de hierro/ y plumaje de piedra/ invertidos en cuatro geranios blancos. / / VI Bajo la lluvia, el dócil/ encorvarse/ de las varas de nardos,/ naranjas/ y blancos./ Y la silueta imperturbable/ del cisne de cemento.// VII No cantan cuando mueren./ Cuanto más, acaban confundidos / con la maleza / o bien en una pila/ de hierros oxidados". (DÍAZ, 1998, p. 15-20). 
intimidad, de la historia colectiva? Objetos resituados, sacados de su contexto habitual, como en el poema de Díaz, pero no fuera de contexto. Objetos que definen el contexto y también al sujeto, como en el poema que abre Seudo, el segundo libro de Martín Gambarotta:

Un racimo de bananas

jóvenes en la canasta

casi rectas:

la cáscara amarilla

verde y sin lunares.

Cuando se acabe la fruta, la merluza

los ajíes, el té amargo, nos vamos de acá.

A cualquier lado. A las plantaciones.

A un lugar donde no existan los tenedores. ${ }^{6}$

¿Una promesa de un mundo sin objetos? ¿Una utopía de buen salvaje? Los tenedores son, en este poema, que en su tercera estrofa desarma la naturaleza muerta presentada en las dos primeras, objetos etnográficos. ¿de dónde habría que irse? ¿de la naturaleza muerta como clisé de la disposición de los objetos? ¿de la cultura? Podría mover este poema, este tenedor, hacia un extremo de la mesa crítica; tal vez podría moverlo hacia un punto intermedio o hacia el centro para ver de otra manera, no necesariamente lineal, el movimiento de un corpus, las certezas que cruzan una poética, la destrucción (en un futuro no muy lejano) del objetivismo, ${ }^{7}$ una de las líneas

\footnotetext{
${ }^{6}$ GAMBAROTTA, 2000, p. 9.

${ }^{7}$ Sobre fines de los 80, en Argentina, comenzó a hablarse de poesía objetivista, sobre todo en el interior del Diario de poesía (1986). De hecho, los principales objetivistas forman parte de esta publicación: Jorge Aulicino, Daniel García Helder, Samoilovich, Martín Prieto. La
} 
fuertes de la poesía argentina de los ‘90. En todo caso, apuesto, esos tenedores forman parte del "sistema de objetos" de la poesía de los ‘90, son una de las formas de tramar los modos de relación entre estos y el sujeto, la experiencia.

Objetos, entonces, que vienen a reemplazar a otros objetos; entran al poema desplazando configuraciones anteriores, tachando adjetivos; se acercan al sujeto, lo identifican, pero también se alejan del sujeto, lo desconocen o lo vuelven irremediablemente otro. La poesía de los '90 no trae siempre nuevos objetos, pero los trae siempre de nuevo. Los objetos son tan relevantes que su presencia debe consignarse (son lo que se ve), y por eso el leitmotiv del cuadro o de la foto son tan importantes, son la instancia pedagógica, didáctica de un proceso de escritura, la pauta de lo que en algún momento llamé caligrafía de la imagen objetiva, esa combinación de formas, colores; una determinada sintaxis de la imagen acompañada por un fraseo controlado.

Pero me detendré ahora en una serie más homogénea que aparece reiteradamente en la poesía de los ‘90, en algunos paisajes, en algunas porciones de espacio de inscripción de objetos industriales o posindustriales y artesanales que arman constelaciones del orden productivo, económico y familiar.

El gesto es, claramente, en algunos poemas, el de mirar de nuevo, limpiar el poema, limpiar los ojos. En "Pintores dominicales en Puerto Piojo", uno de los poemas de Poesía civil (2001) de Sergio Raimondi, este reinicio aparece planteado de manera programática:

recuperación del objetivismo norteamericano se da, en esa instancia, sobre todo, a partir de la figura de William Carlos Williams, o mejor, a partir de su poesía fotográfica. Sin embargo, la figura faro para los integrantes del objetivismo será EzraPound, fundador del Imagismo. Gambarotta también está relacionado con el objetivismo norteamericano, pero en su caso, como en el de Raimondi, las lecturas se extienden a Oppen, Rakosi, Zukofsky. He desarrollado un análisis de esta poética en Caligrafía tonal - ensayos sobre poesía. 


\section{(...) Cuarenta años atrás}

o el domingo pasado, la tela recorta lo mismo:

la estela fugitiva que la lancha de los pescadores

dibuja al alejarse hacia las islas mientras el sol

cae o la bienvenida ruidosa que las gaviotas dan

en la mañana a los marinos o ásperas puestas

las redes a secar sobre cajones de madera escrita.

$\mathrm{Al}$ fondo del lienzo indefinida la mancha gris

de las construcciones: los elevadores ingleses

de chapa ayer, hoy los silos y el muelle de Cargill

o la serie de tanques del proyecto Mega. Eso

que no es, no será, no fue belleza, está atrás, lejos. ${ }^{8}$

Sacar, entonces, de la tela (del poema) aquello que se ha convertido en pintoresquismo artístico - la escena portuaria, la estela de los barcos, las gaviotas-, para dejar que las cosas se presenten, en este caso, con la contundencia del paisaje tecnológico. Poner, en el centro del poema, "la mancha gris", indefinida, la que no pintó la tradición y tiene que ver no sólo con el presente sino también con un pasado, el de "los elevadores ingleses de chapa ayer", el de "los silos y el muelle de Cargill", hoy. Así, la extrañeza de los poemas de Raimondi, tendrá que ver con que aparecen allí tolvas, guinches, plataformas marítimas, caños de gas. El tratamiento de estos nuevos objetos no será nostálgico, pero tampoco estará impulsado por un espíritu futurista, celebratorio de las máquinas, ni por un ojo naturalista, como el de cierta literatura social del grupo argentino de Boedo, de Elías Castelnuovo, por ejemplo. Estas fábricas de Poesía civil, nada tienen que ver con las de Castelnuovo y con su versión monstruosa del mundo del trabajo. En realidad, la omnipresencia de este paisaje maquínico entra en tensión con otra serie en la poesía de Raimondi, la de los objetos artesanales que asumen su verdadera forma en una práctica, como en el

${ }^{8}$ RAIMONDI, 2001, p. 110. 
poema "Para hacer una torta sin leche"; 9 lo que vale en estos casos es la puesta en escena del proceso de factura, la impronta de singularidad de los objetos relacionada fuertemente con la experiencia. ${ }^{10}$ Además, el objeto artesanal envía, una y otra vez, a desnaturalizar los sentidos que persisten, las adherencias históricas, políticas y también poéticas o artísticas. Así, en Relapso + Angola (2004), de Martín Gambarotta, el motivo de la bandera de Angola, que son en realidad distintas banderas, se lleva también al momento de su producción: "En una placa de radiografía limpiada con lavandina/ se boceta lo que después se corta con una trincheta/ por el borde sobre una superficie de linóleo/ como piezas de un rompecabezas cada parte es autónoma/ la rueda dentada, el machete, la estrella, las franjas;/ sobre un vidrio pulcro se coloca la tinta con espátula / mezclándola con unas gotas de aceite de lino". ${ }^{11}$ ¿Desaparece la bandera? Ciertamente no se trata de la bandera política, de

\footnotetext{
${ }^{9}$ RAIMONDI, 2001, p. 66.
}

${ }^{10}$ En tanto proyecto poético, de hecho, las redes de objetos industriales o posindustriales estarán siempre asediadas por el ejercicio de sabotaje, como en el poema "Extraños ruidos en la tolva": "ahora los guantes poseen apellido y número de legajo/ pero no la herramienta que el operario como al descuido/ desliza en la bolsa de soda en perlas y que el vigilante/ deberá dar por perdida con la consiguiente multa para él./ Días más tarde, al realizarse la descarga de los vagones / en el muelle, el responsable de los silos de almacenamiento / oirá primero el golpe seco del hierro y luego el estallido/ de los metales con que ha sido construida la hermosa tolva." (RAIMONDI, 2001, p. 30). Si bien aquí se trata de una acción, la cita importa en tanto propone una alteración (o una posible destrucción) de los objetos tecnológicos y la aparición de una serie de objetos artesanales. En realidad podría leerse este poema como el gesto de hacer saltar la serie de objetos, el sistema de objetos, como lo denomina Baudrillard, como reactivación de su valor de uso, más que del valor de cambio.

${ }^{11}$ GAMBAROTTA, 2004, p. 77. 
la de la revolución angoleña, esa que en el libro está asociada a la poesía de la nueva trova cubana, a Silvio Rodríguez. Una bandera que no simboliza nada porque es pura materialidad, porque aún no está hecha. Y si no está hecha no es el emblema de nada. Volver al proceso de constitución de un objeto es sacarlo de la serie habitual y a la vez podría leerse como una necesidad de empezar de cero, como si las leyes de los objetos políticos no existiesen, o más bien, como si la serie de los emblemas políticos debiese ser entendida solamente o en principio, como trabajo artesanal y no como idea. Otra vez, se trata de limpiar los objetos. En este caso, como en los poemas de Raimondi citados, lo que se desplaza es la poesía social, la del grupo de Boedo; pero sobre todo la poesía política argentina o latinoamericana de los años '60. Las banderas que flamean, justamente, en el poema de Gelman titulado "Desfile popular del 11 aniversario de la R. P. China", cuyo verso de cierre es "como Pequín, como banderas, casos íntimos, rostros y la Revolución".${ }^{12}$ La bandera de Gambarotta podría ponerse en relación con la torta cuya receta va "diciendo" una mujer en el poema de Raimondi, pero también con el cisne de cemento de Marcelo Díaz, que es un objeto industrial y funciona como adorno que discute toda la simbología anterior del ave. Pero también, en otro sentido, podría compartir la mesa, la constelación hipotética, con algunos desechos de la poesía de Mario Ortiz, en tanto se privilegia en un caso el origen artesanal y en otro, la destrucción de un aparato, un motor, por ejemplo, que ha sido un objeto de uso y descansa sobre su propia historia que es también la de ciertos sujetos.

El momento de factura, entonces, pero también el de desaparición (aunque veremos que esta no existe). De hecho, otro de las escenarios habituales de presentación de los objetos

${ }^{12}$ GELMAN, 1989, p. 118. Aclaro que el poema pertenece a Velorio del solo, cuya primera edición es de 1961. 
industriales en la poesía argentina de los ‘90, es el del basural, tal como aparece, por ejemplo, en Punctum (1996) de Martín Gambarotta: "En la calle,/ cerca de un lote con partes quemadas / de lavarropas, las llamas tatuadas en el esmalte blanco,/ heladeras en desuso/ dejadas al fondo del baldío, $(. . .)^{\prime \prime} \cdot{ }^{13}$ Lo que en Punctum parece ser una presencia muda, asociada a la imposibilidad de quien habla de nombrar las cosas, ${ }^{14}$ una estampa posindustrial, en "Tomas para un documental" de Daniel García Helder, ${ }^{15}$ una serie de poemas escritos entre 1992 y 1995, adquiere una cualidad ominosa y convive con ese paisaje que Raimondi pondrá en primer plano en 2001, en Poesía civil, el que había tapado el pintoresquismo: "Una luz rielando en las aguas negras del antepuerto/ y entre explosiones de motor un par de remolcadores van haciendo girar / ciento ochenta grados al Barbican Spirit, de bandera filipina,/ entre cuyos mástiles negros se hamaca tendida la estela / luminosa del año que pasó, número mil novecientos noventa y uno". ${ }^{16}$ Más adelante, el reverso del pintoresquismo será casi un dato definitivo: "Vi los barcos podridos las quillas de esos barcos también/ podridas las gomas los tarros maderas corchos bidones / todo lo que flota por naturaleza o con ayuda del aire/ que contuviera en

${ }^{13}$ GAMBAROTTA, 1996, p. 32.

${ }^{14}$ Ya al principio del poema leemos: "Rodeado de cosas sin nombre a mí también / me hubiera gustado empezar esto/ con: de noche junto al fuego/ pero acá/ no hay, salvo en potencia, fuego". GAMBAROTTA, 1996, p. 8.

${ }^{15}$ Fragmentos del inédito "Tomas para un documental" aparecieron en el sitio Poesia.com (Buenos Aires, 1996), en las revistas Punto de Vista (Buenos Aires, N 57,1997), La Modificación (Madrid, 1998), Matadero (Santiago de Chile, No 103, 2002), en Monstruos, la antología a cargo de Carrera (Buenos Aires: FCE, 2001) y otras de poesía latinoamericana. La selección que analizo en este caso es la de Punto de Vista.

${ }^{16}$ GARCÍA HELDER, 1997, "II", p. 1. 
su interior flotando en el agua bofe / en la pura inconciencia con visos de aceite quemado".${ }^{17}$ Los objetos de esta serie tienen una cualidad saliente, son temporales, o más bien, son el punto exacto en el que los tiempos heterogéneos se unen: en el presente está inscripto el pasado y, también, el futuro:
(....) los muros de ladrillo colorado entre la vuelta de Berisso y la de Badaracco donde el cielo se pone del mismo color de la arena vítrea que ahí se amontona, o como esa otra ferretería vieja de Barracas cuyo nombre en la chapa oxidada lleva un buen rato descifrar pero al final emerge, casi un recuerdo: DEL PORVENIR. ${ }^{18}$

La sintaxis es la que habilita la fusión de los tiempos. En el cartel de la ferretería casi ilegible, antiguo, se lee su nombre, del Porvenir. De tal modo que el pasado es un recuerdo de lo que vendrá. Los objetos, como se dijo, comprimen el tiempo y son restos de un pasado no demasiado lejano, restos históricos, casi podría decirse, fósiles que persisten en el presente y ya no serán presencia muda sino que tienen algo para decir.

Esta serie de objetos que hemos revisado hasta el momento en algunos poemas, arman la red (a veces de residuos) de una temporalidad fuertemente política. Los poemas insisten en la materialidad de esos objetos, en sus funciones, en sus contextos. Como si fuese necesario (y para este proyecto poético lo es) nombrar de nuevo, instalar los objetos en el poema nuevamente. Por momentos, esos objetos podrían pensarse como souvenires. El cartel de la ferretería en el poema recién citado de García Helder es un ejemplo. Es una porción del pasado, funciona metonímicamente, por contigüidad y permite hipotéticamente reponer la ausencia de aquello que estuvo en la poesía social de

\footnotetext{
${ }^{17}$ GARCÍA HELDER, 1997, “VI”, p. 2.

${ }^{18}$ GARCÍA HELDER, 1997, “II", p. 2.
} 
los '20 y en el tango, pero también en los ‘60. Un resto, un fósil (como una flor dentro de un libro) que conecta con toda esa serie. Pero la idea de souvenir debería redefinirse ya que el cartel no envía a una afectividad personal sino a una sensibilidad histórica colectiva; aunque de alguna forma, ese resto antiguo tiene la función, como dice Susan Stewart, de "envolver el presente en el pasado". Sin embargo, los souvenires son, dice también Stewart, objetos mágicos; objetos de deseo que envían a "un lugar de origen que debe permanecer inaccesible ${ }^{\prime 19}$ y en este caso, el cartel, es el descubrimiento - por llamarlo de algún modo- de un ojo arqueológico. No habría, en la metonimia, recuerdo a recuperar simplemente; porque el cartel hablaría todas las lenguas, la del pasado, la del presente y, como se ha visto, la del porvenir. Por otra parte, el objeto siempre estará inscripto en el espacio, sólo se entiende en ese contexto que le da sentido.

En uno de los libros de Mario Ortiz aparece una escena en la que los objetos viejos permiten indagar aún más esta persistencia: el espacio de observación es en Crítica de la imaginación pura el de un terreno, al costado de un gallinero; allí el poeta encuentra una carcaza de radio Plymouth, una lata de café, una lata de Nesquik, un enorme motor inglés, una cafetera de lata enlozada. Todos estos objetos son observados minuciosamente y el observador repondrá las distintas instancias temporales y, sobre todo, el valor de uso de cada uno. Así, a partir de la radio llegamos a la historia de la primera audición radiofónica argentina (cuando transmitieron Parsifal de Wagner), al momento de cierre de LU7 Radio General San Martín (y entonces, a la última dictadura argentina). Los objetos se redefinen en distintas historias del mundo del trabajo, de la economía, la política y del mundo propio, de la infancia. Toda la historia se abre a partir de las cosas y estas son, como dice

${ }^{19}$ STEWART, 2013, p. 222. 
Baudrillard, pura presencia, ya que estarán atravesadas por lo afectivo, algo que no sucedía en los poemas de García Helder, Gambarotta o Raimondi. En los poemas de Ortiz, el objeto funciona dentro de una serie ciertamente más aleatoria. Y la reconstrucción arqueológica permite pensarlos como fósiles también; sin embargo los deshechos abren, como hemos dicho, campos imaginarios amplios. Claramente, porque además lo enuncia el poema, las cosas, sus restos, encriptan una historia facetada: "El motor Ruston \& Hornsby recuesta su pesadez sobre invisibles líneas temporales, espaciales, utilitarias, morales, políticas e imaginarias. Las palabras hacen visibles esas líneas vectoriales como el polvillo en suspensión que marca la trayectoria de un rayo solar al filtrarse por las rendijas de una persiana" ${ }^{20}$

Pero además, hay una ruptura, un deslizamiento en la serie de objetos que no estaba en el resto de los poemas. El poeta usa la cafetera encontrada como "instrumento óptico", mira el resto de los objetos por un agujero milimétrico producido por el óxido: "A través del orificio, se me aparece el interior de la lámpara como un ensamble de hilos, plaquetas diminutas y platillos superpuestos, similar a una sonda espacial que navega en una ampolla, a veleros encapsulados en una botella". ${ }^{21} \mathrm{Y}$ allí se abre un despliegue metafórico porque el interior de la radio puede ser (se transforma de hecho) una sonda espacial, o en un velero dentro de una botella. Si bien la cafetera funciona como instrumento de observación, el costado científico de la práctica está minado por la metáfora, que es, como dice Oyarzún, la ley del objet trouvé: ${ }^{22}$ oficia como extensión del ojo, y en este sentido, como lámpara mágica. ${ }^{23}$ No es el azar el que lleva al poeta a encontrar

\footnotetext{
${ }^{20}$ ORTIZ, 2011, p. 19.

${ }^{21}$ ORTIZ, 2011, p. 12.

${ }^{22}$ OYARZÚN, 1979, p. 171.

${ }^{23}$ Hay otro objeto mágico, objeto de desplazamiento, en Crítica de la imaginación pura de Mario Ortiz. Se trata de una piedra, que encontró
} 
los desechos en el terreno pero este se despliega en el ejercicio de observación. Bello, podría decirse, como el encuentro de un velero embotellado, una sonda espacial y una radio en un gallinero, mimando el enunciado de los ya famosos versos de Lautréamont recuperados por André Breton en el Manifiesto surrealista de 1924 ("Bello como el encuentro fortuito de un paraguas y una máquina de coser sobre una mesa de disección"). Ahora bien, el objet trouvé, en tanto saca la cosa de su circuito de uso, de su funcionamiento en la cotidianeidad, es una de las facetas del mundo de objetos, sostenidos también por coordenadas "temporales, espaciales, utilitarias, morales, políticas e imaginarias".

En aquel proyecto de los '90, que supuso borrar de la tela (del poema) ciertos objetos cargados ya de valor simbólico y recuperar su materialidad de manera exhaustiva; en aquel proyecto que tensionó la figura del sujeto con las cosas, la poesía de Ortiz podría leerse como un ejercicio de sobrepujamiento de los objetos hasta transformar a algunos de ellos en pequeños azares o en talismanes (en diminutos mundos). Tal vez, entonces, el motor de Crítica de la imaginación pura, podría ocupar un lugar en el lienzo, semejante al de los tenedores de Gambarotta. Porque plantean dos instancias bien diferentes sobre los objetos, la del abandono necesario que implicaría una utópica tabula rasa que no por esto deja de ser histórica, y la de la apertura de los objetos -bajo el asedio de la mirada minuciosa, o convertidos ellos mismos en superficie a través de la cual se mira- hacia tramas imaginativas en las que, sin embargo, el presente es siempre reminiscente, como dice Didi-Huberman. ${ }^{24}$

junto a su hermana en un barrio de Bahía Blanca. En un momento el poeta al mirar a trasluz la piedra negra con bordes verdosos e inmediatamente se para "sobre la superficie de un lago verdoso, como los mosquitos que, en su liviandad, esperan durante horas sobre el agua mullida" (ORTIZ, 2011, p. 28).

${ }^{24}$ DIDI-HUBERMAN, 2006, p. 135. 
Objetos, uno y otro, que puestos sobre la mesa de la poesía de los '90 tensan una escena poética.

En la mesa crítica imaginada, sin dudas, este motor, o la carcaza de radio de Ortiz, deben estar junto a los silos, o la central termoeléctrica de la poesía de Raimondi, al barco de bandera filipina del poema de García Helder, a las heladeras quemadas y a la bandera angoleña de Gambarotta, también al cisne de cemento de Marcelo Díaz. Algunos de esos objetos descansan sobre líneas marcadamente económicas y políticas, otros sobre líneas utilitarias y sobre la negación de ciertas líneas morales, otros se abren en líneas imaginarias. Todos ellos descansan sobre, dice Ortiz (y yo diría están hechos de) líneas temporales heterogéneas; y en todos los casos el contexto, la superficie sobre la que se encuentran los objetos -un jardín emplazado en un barrio, una enorme explanada de cemento, un río podrido, un tablero de trabajo, un descampado, un gallinero- los define a la vez que propone nuevos espacios de combinación de los objetos, de percepción de los mismos.

Hacer volver a los objetos, como ya dije, supone reponer un espacio y una temporalidad que parecían perdidos en el circuito omnívoro de las mercancías. Estas son las leyes del "sistema de objetos" 25 de los '90, las que pueden reponerse a partir de su descripción pero también de la puesta en común en una mesa crítica. Se trata, claro, de una mesa de trabajo en la

${ }^{25}$ BAUDRILLARD, 1969, p. 2. Utilizo la expresión de Baudrillard porque de algún modo, estos poemas abordados están hablando de ese mundo cambiante, exponencialmente creciente, inclasificable de objetos, aunque el recorte temporal supone también un período posindustrial. Lo que se propone Baudrillard en su libro es analizar "este sistema 'hablado' de los objetos, es decir" el "sistema de significados más o menos coherente que instauran (...)". El uso se basa, sobre todo, en la decisión de abordar los objetos y no las figuras literarias. 
que el movimiento puede arrojar, arrojará, otros interrogantes, porque como dice Didi-Huberman "La mesa es mero soporte de una labor que siempre se puede corregir, modificar, cuando no comenzar de nuevo". ${ }^{26}$

(Tradução de Mariane Tavares)

\section{Referências bibliográficas}

BENJAMIN, Walter. Libro de los pasajes. Madrid: Akal, 2005. Edición a cargo de Rolf Tiedemann. Traducción de Luis Fernández Castañeda, Isidro Herrera y Fernando Guerrero.

"Desembalo mi biblioteca. Un discurso sobre el arte de coleccionar" y "Zentralpark". Cuadros de un pensamiento. Buenos Aires: Imago Mundi, 1992; pp. 105-116 y 173-213. Selección, cronología y posfacio de Adriana Mancini. Traducción de Susana Mayer.

BAUDRILLARD, Jean. El sistema de los objetos. México: Siglo XXI, 1969. Traducción de Francisco González Aramburu.

CABANNE, Pierre. Conversaciones con Marcel Duchamp. Barcelona: Anagrama, 1972. Traducción de Jordi Marfá.

CLIFFORD, James. "Sobre el surrealismo etnográfico" y "Parte 3. Colecciones". Dilemas de la cultura. Antropología, literatura y arte en la perspectiva posmoderna. Barcelona: Gedisa, 1995. pp. 159-188 y pp. 227-300. Traducción de Carlos Reynoso.

DELEUZE, Gilles.Pintura - el concepto de diagrama. Buenos Aires: Cactus, 2012.

DÍAZ, Marcelo. Berreta. Buenos Aires: Libros de Tierra Firme, 1998.

DIDI-HUBERMAN, Georges. Ante el tiempo - Historia del arte y anacronismo de las imágenes. Buenos Aires: Adriana Hidalgo, 2006. Traducción de Omar Antonio Oviedo Funes.

${ }^{26}$ DIDI-HUBERMAN, 2010, p. 18. 
-Dispar(at)es 'Leer lo nunca escrito'”. Atlas ¿Cómo llevar el mundo a cuestas?. Catalógo. Madrid: MNCERS, 2010; p. 14-58. GAMBAROTTA, Martín. Punctum. Buenos Aires: Libros de Tierra Firme, 1996.

Seudo. Bahía Blanca: Vox, 2000.

- Relapso + Angola. Bahía Blanca: Vox, 2004.

GARCÍA HELDER, Daniel. "Tomas para un documental”. Punto de Vista. Buenos Aires: No 57, 1997.

GELMAN, Juan. Violín y otras cuestiones/El juego en que andamos/ Velorio del solo/ Gotán. Buenos Aires: Tierra Firme, 2a edición, 1989.

ORTIZ, Mario. Cuadernos de Lengua y Literatura $V$. Al pie de la letra. Bahía Blanca: 17 grises editora, 2010.

pura. Montevideo: La Propia Cartonera, 2011.

OYARZÚN, Pablo. Anestética y ready-made. Santiago de Chile: Universidad ARCIS [1979, tesis]. En http:/ / www.philosophia.cl/ biblioteca/Oyarzun/Anestetica\%20del\%20ready-made.PDF PORRÚA, ANA.Caligrafía tonal - ensayos sobre poesía. Buenos Aires: Entropía, 2011.

RAIMONDI, Sergio. Poesía civil. Bahía Blanca: Vox, 2001.

STEWART, Susan. El ansia. Narrativas de la miniatura, lo gigantesco, el souvenir y la colección. Rosario: Beatriz Viterbo editora, 2013. Traducción de Adriana Astutti.

WARBURG, Aby. Atlas Mnemosyne. Madrid: Akal, 2010. Traducción de Joaquín Chamorro Mielke. Edición de Martín Warnke. 


\section{Resumo}

Este ensaio busca refletir sobre o conceito de "sistema dos objetos" (Baudrillard), tendo como corpus a poesia argentina mais recente, na qual a presença das coisas surge como elemento importante. $\mathrm{O}$ dispositivo crítico utilizado é a noção de tabula rasa, tal como a pensou Didi-Huberman, ou seja, como superfície de inscrição que permite recuperar significados, deslocar sentidos e compreender a utilização dos objetos, no poema, como processo e movimento que tece redes diversas. A poesia de Daniel Garcia Helder, Marcelo Díaz, Sergio Raimondi e Martín Gambarotta permite indagar criticamente a tradição e as poéticas existentes em cada época. Nesse sentido, elegem-se as figuras do objeto arqueológico ou etnográfico, o denominado "objet retrouvé" e o "souvenir", na medida em que tais artefatos materializam as distintas relações entre materialidade e valor simbólico, entre valor de uso e valor de troca, entre natureza e cultura, entre passado e presente, entre objetividade e subjetividade, entre mercantilização e artes manuais.

\section{Resumen}

El trabajo aborda un "sistema de objetos" (Baudrillard) en un corpus de poesía argentina reciente, en el que la presencia de las cosas insiste como rasgo saliente. El dispositivo crítico utilizado es la noción de mesa (tabula rasa) tal como la entiende Didi-Huberman, como superficie de inscripción que permite recuperar significados, desplazar sentidos y entender el ingreso de los objetos al poema como proceso, como movimiento que teje redes diversas. El armado de series en la poesía de Daniel García Helder, Marcelo Díaz, Sergio Raimondi y Martín Gambarotta, permite indagar críticamente la tradición y las poéticas de época. En este sentido se eligen las figuras del objeto arqueológico o etnográfico, el objet trouvé y el souvenir que dan cuenta de 
distintas relaciones entre materialidad y valor simbólico, entre valor de uso y valor de cambio, entre naturaleza y cultura, entre pasado y presente, entre objetividad y afectividad, entre mercantilización y artesanado. 
